\title{
Covid-19 and Safety in the Cath Lab: Where We Are and Where We Are Headed
}

\author{
Giordana Zeferino Mariano, ${ }^{\circledR}$ Viviana Guzzo Lemke, ${ }^{\circledR \oplus}$ Maria Sanali Moura Paiva, ${ }^{3 ®}$ Gláucia Maria Moraes de Oliveira ${ }^{4}$ \\ Hospital São João Batista, ${ }^{1}$ Criciúma, SC - Brazil \\ Hospital das Nações, Curitiba, ${ }^{2} P R-$ Brazil \\ Universidade Federal do Rio Grande do Norte (UFRN), ${ }^{3}$ Natal, RN - Brazil \\ Universidade Federal do Rio de Janeiro (UFRJ), ${ }^{4}$ Rio de Janeiro, RJ - Brazil
}

The COVID-19 pandemic, caused by the betacoronavirus SARS-CoV-2, has rapidly spread worldwide from the city of Wuhan, China. Since its beginning, it has affected more than 2,700,000 individuals and caused almost 185,000 deaths in 185 countries, compounding the difficulties in medical healthcare worldwide. By April 23, 2020, Brazil had registered almost 47,000 confirmed cases and 3,000 deaths. ${ }^{1}$

COVID-19 aggravates the inequalities and uncertainties of science in general. This is no different when it comes to the heart. Unlike other epidemics caused by respiratory viruses, COVID-19 affects the heart, not only because most confirmed cases and deaths involve individuals with hypertension, heart failure, arrhythmias and coronary artery disease, but also because the disease is associated with a higher number of cardiac complications, such as myocardial injury, cardiogenic shock, Takotsubo syndrome, pulmonary embolism, myocarditis and arrhythmia. ${ }^{2}$ Apart from inflammation, endothelial activation, oxidation of low-density lipoproteins, platelet activation and tissue factor expression caused by respiratory virus epidemics, such as severe acute respiratory syndrome (SARS) and Middle-East respiratory syndrome (MERS), poor COVID-19 prognosis is compounded by the deleterious effect of the association of treatment drugs (chloroquine/ azithromycin) that can cause malignant arrhythmias in patients with heart disease. ${ }^{3}$

\section{Keywords}

Coronavirus; COVID-19; Pandemics; Pathological Conditions, Signs and Symptoms; Fever; Cough; Dyspnea; Fatigue; Diarrhea; Chest Pain; Mental Confusion; Myalgia, Cardiovascular Diseases/complications; Safety.
The challenges concerning COVID-19 are huge, because it tests us all - patients, healthcare personnel, health systems and the general population. In light of this, the importance of the safety of healthcare workers has never been so emphasized. ${ }^{2}$

Working in a hospital during a pandemic of a highly contagious disease, such as COVID-19, reminds healthcare workers of the need to reinforce all safety measures inside a cardiac catheterization laboratory (CCL). That is because, in addition to the cardiovascular alterations due to COVID-19, patients with cardiovascular diseases, such as acute myocardial infarction and advanced structural diseases, continue to require interventional procedures.

Therefore, the safety measures for healthcare professionals and patients become even more important during the COVID-19 pandemic. Some of the safety issues that might affect both patients and healthcare personnel are as follows: ionizing radiation, equipment, and contact with chemical and biological agents. All health professionals in contact with patients should follow the local and national guidelines for infection control and use of personal protective equipment (PPE), which should be available and on hand for all staff members. In addition, strict adherence to all safety rules required for a catheterization procedure indication should be encouraged; moreover, all urgent cases should be prioritized, and all routine cases postponed if this carries no loss to either prognosis or the patients' quality of life. ${ }^{4}$

The Brazilian Society of Interventional Cardiology (SBHCI) has published a position statement on some general measures to tackle COVID-19: limitation of social exposure; adoption of stricter personal hygiene habits; home confinement of individuals with the mild 
form of COVID-19; hospital support with isolation for patients with the severe forms of the disease; quarantine for the close contacts of suspected cases; priority allocation of healthcare resources to urgent and emergent cases; protection of the professionals involved in patients' care. In addition, regarding specifically the CCL, the SBHCI recommends: to postpone elective procedures in patients with confirmed or suspected COVID-19; to limit the performance of CCL procedures to cardiovascular emergencies, and, for the other cases, procedures must be postponed until the non-infecting stage of disease; in CCLs with multiple procedure rooms, one should be dedicated to the treatment of suspected or confirmed COVID-19 patients. $^{5}$

During the COVID-19 pandemic, the general safety protocols and those concerning CCL procedures, as well as the safety measures for patients and healthcare personnel need to be reviewed, because that infection increases the requirements for indication and effectiveness of the procedures performed.

\section{Safety measures in the procedure preparation stage}

A study conducted in China with 72,314 patients with COVID-19 (44,672 laboratory-confirmed cases, 16,186 suspected cases, and 10,567 clinically diagnosed cases) has reported fever, cough, dyspnea, myalgia, fatigue and diarrhea as the most common symptoms. Other signs and symptoms have been reported, such as sore throat, chest pain, mental confusion, and lethargy. The authors have highlighted that COVID-19 had a benign course in $80 \%$ of the cases, and that many patients, although asymptomatic, could carry the virus. ${ }^{6}$ It is worth noting the importance of the differential diagnosis of dyspnea and fatigue, especially when associated with the other symptoms.

During a respiratory pandemic, patients and their families should be informed about the risks of contamination, despite all additional measures taken to minimize them. Because the number of elective procedures will be drastically reduced during that period, the length of hospital stay is predicted to be the minimum necessary for each protocol consensually elaborated. ${ }^{7}$ Moreover, defining a procedure as elective requires clinical judgement, because postponing it might have effects that will increase the likelihood of decompensation and adverse events during the pandemic, such as in high-risk patients with unstable angina. Therefore, the decision about performing a procedure should be individualized and based on the patient's risk and benefit analysis. ${ }^{8}$

Despite the adoption of measures to reduce exposure, healthcare personnel shortage should be anticipated based on the likelihood of the removal of infected, exposed, at-risk and quarantined healthcare personnel. Particular attention should be given to avoid simultaneous exposure of healthcare professionals sharing the same skill set to prevent simultaneous contamination, especially in teaching institutions where the staff usually act together. ${ }^{4}$ In addition, it is worth emphasizing the importance of reducing as much as possible the circulation in the procedure room to ensure the minimum safety threshold established in CCL procedural protocols. ${ }^{4}$

It is worth noting that patients with suspected or confirmed COVID-19 should ideally undergo procedures at the end of the day or in CCL rooms dedicated to COVID-19, when available, because of the need for terminal disinfection. ${ }^{4}$

Patients already intubated represent a lower risk of contamination to healthcare personnel, because they are on closed-loop ventilation. In patients with suspected or confirmed COVID-19 who need orotracheal intubation, this intervention should be performed before arrival to the CCL; in addition, intubation should be considered as early as possible in borderline patients to avoid the need for an urgent procedure and to minimize the contamination of the staff. ${ }^{4}$

\section{Safety measures concerning the procedures}

Healthcare personnel exposure and benefits to patients should be balanced for all interventional procedures. For example, during a respiratory epidemic, for hemodynamically stable patients with COVID19+ and ST-segment elevation myocardial infarction, fibrinolysis might be an alternative according to some authors; ${ }^{6,9}$ however, the length of hospital stay waiting for coronary angioplasty after fibrinolysis should be carefully considered.

It is worth noting that COVID19 is spread via respiratory droplets and contact with surfaces on which the virus can last for long periods, such as cell phone, keyboard, mouse and door handles, thus, the procedure duration should be reduced to a minimum. ${ }^{10,11}$ Moreover, patients with suspected or confirmed COVID-19 should be using a face mask upon arrival to the CCL and continue to use it during procedure preparation and the procedure itself. ${ }^{4}$ 
All CCL personnel should wear PPE, including FFP2/N95 respirators, goggles, full face shields, disposable caps, gowns, surgical gloves, and shoe covers, during the entire procedure, because of the potential for those patients' clinical deterioration and the consequent risk that comes with intubation, aspiration and cardiopulmonary resuscitation. In addition, CCL staff should be well educated in the proper donning and doffing of PPE because of the high likelihood of contamination involved in the process..$^{3-5}$

It is worth noting that myocardial injury has been reported in $7 \%$ of the patients with COVID-19 and might correspond to type 2 myocardial infarction or myocarditis. ${ }^{11}$ Thus, no effort should be spared in reaching the differential diagnosis before the procedure with the aid of imaging tests, such as point-of-care echocardiography.

In addition, it is worth emphasizing that percutaneous coronary intervention should only be performed to the culprit vessel, unless a nonculprit lesion is deemed unstable or in the presence of multiple culprit lesions. ${ }^{12}$

\section{Post-procedure safety measures}

During the pandemic, in anticipation of a surge in hospitalization required for COVID-19 infected patients and because not only most inpatient beds will be made available for COVID-19 treatment, but also to avoid additional contamination, hospital discharge will occur earlier for stable patients who might be followed up via telemedicine. ${ }^{12}$

Within the CCL, all nonessential equipment should be moved out of the procedure room or covered with clear drapes before patient's arrival to the room, and the same applies to the control and post-procedure recovery rooms. After a procedure in a patient with COVID-19, thorough terminal disinfection can be performed with ultraviolet light. ${ }^{12}$

The standard positive pressure ventilation system of the CCL consists of an air-handling unit that distributes conditioned air to different functional units, including the procedure, post-procedure, and control rooms. Positive pressure with adequate air changes can rapidly eliminate the virus from the environment; in addition the risk of cross-contamination from airborne infections has been shown to be low if the personnel is protected with appropriate PPE. ${ }^{9}$ The positive pressure ventilation system should be extended to the rooms associated with the procedure.
It is worth noting that the inflammatory state of patients with COVID-19 often determines a hypercoagulable condition that requires additional use of heparin. ${ }^{11}$

Figure 1 shows the safety recommendations for CCL procedures during the COVID-19 pandemic. Those written in bold letters should receive special attention during the COVID-19 pandemic.

\section{Safety and protective measures for healthcare workers}

During the COVID-19 pandemic, all material used for invasive procedures, including the equipment for anesthesia, orotracheal intubation and mechanical ventilation, in addition to PPEs, should undergo a daily check and be readily available for easy and rapid use to minimize the work and burnout of healthcare professionals. ${ }^{13}$

The PPE should be removed preferably in an anteroom. If no anteroom is available, doffing of PPE should be done inside the procedure room, at the end of the procedure and after the patient has been transferred away, except for the PPE for respiratory protection, which must be removed outside the procedure room. ${ }^{13}$

Post-procedure visits should be performed by the lowest number possible of professionals; moreover, discussions about additional management should be converted to an online or telephone format, and the same applies to morning CCL rounds. ${ }^{12-14}$

Most sanitizers contain alcohol at different concentrations and are used for cleaning and disinfecting high-touch surfaces (floor, walls, ceiling, and countertops), a precaution that is important during the COVID-19 pandemic. SARS-CoV-2, a single-strand RNA virus, is sensitive to ultraviolet radiation and heat, being inactivated by lipid solvents, such as ether (75\%), ethanol, sanitizers containing chlorine, peroxyacetic acid and chloroform, except for chlorhexidine. ${ }^{15}$

Terminal disinfection of the procedure room at the end of each procedure is highly recommended during the COVID-19 pandemic. Disposable PPE, sheets, fabric, and sponges contaminated with blood should be placed into a waste container marked with the biological hazard symbol and disposed into a waste bin labeled as 'COVID-19' ${ }^{10}$

Figure 2 shows the general safety items for CCL procedures. Those written in bold letters should receive special attention during the COVID-19 pandemic.

Figure 3 shows the steps for putting on and removing PPE for CCL procedures during the COVID-19 pandemic. 


\begin{tabular}{|c|c|c|}
\hline COVID-19 & \multicolumn{2}{|c|}{ SAFETY RECOMMENDATIONS FOR CCL PROCEDURES } \\
\hline & During the procedure & \\
\hline $\begin{array}{l}\text { Before the procedure } \\
\checkmark \text { Balance of healthcare personnel } \\
\text { exposure against patients' benefits. } \\
\checkmark \text { Anamnesis: identification, weight, } \\
\text { height, indication for exam, } \\
\text { comorbidities, risk factors, tolerance to } \\
\text { decubitus position, history of allergies, } \\
\text { medications being used, previous } \\
\text { complementary tests. } \\
\checkmark \text { Signs and symptoms compatible with } \\
\text { COVID-19 (fever, cough, dyspnea, } \\
\text { myalgia, fatigue, diarrhea, sore throat, } \\
\text { chest pain, mental confusion and } \\
\text { lethargy). } \\
\checkmark \text { Explanation about the informed } \\
\text { written consent and its signature, with } \\
\text { emphasis on contamination risks and } \\
\text { measures to avoid them. } \\
\checkmark \text { Assess all devices in the CCL procedure } \\
\text { room on a daily basis (imaging and } \\
\text { telemetry monitors, computers, image } \\
\text { acquisition devices, contrast injection } \\
\text { pump, anesthesia cart, defibrillator), } \\
\text { which should be readily accessible. } \\
\checkmark \text { Nonessential CCL devices should be } \\
\text { moved out of the procedure room or } \\
\text { covered with clear drapes. }\end{array}$ & $\begin{array}{l}\checkmark \text { Use of proper PPE (apron, gown, surgical } \\
\text { gloves, goggles, full-face shields, N95 } \\
\text { respirators) and training of CCL personnel } \\
\text { on putting on and removing PPE. } \\
\checkmark \text { Patient's positioning with monitoring and } \\
\text { re-checking in the presence of all team } \\
\text { members (patient's identification and } \\
\text { procedure to be performed, COVID-19 } \\
\text { signs and symptoms, medications being } \\
\text { used, with an emphasis on antiplatelet } \\
\text { agents and sexual stimulants, fasting } \\
\text { duration, possible pregnancy). } \\
\checkmark \text { Review of the arterial puncture site. } \\
\checkmark \text { Assessment of contrast type and amount } \\
\text { (previous kidney disease, age, patient's } \\
\text { hemodynamic state, estimated glomerular } \\
\text { filtration rate). } \\
\checkmark \text { Good communication within the team, } \\
\text { with reference and counter-reference, } \\
\text { and continuous training in emergency } \\
\text { protocols (cardiorespiratory arrest, stroke, } \\
\text { anaphylaxis, coronary artery rupture). } \\
\checkmark \text { Talk with the patient for the early approach } \\
\text { to complications (analgesia, nauseas). } \\
\checkmark \text { Support the previous differential } \\
\text { diagnosis of myocardial injury with } \\
\text { imaging techniques, such as point-of-care } \\
\text { echocardiography. } \\
\checkmark \text { Percutaneous coronary intervention should } \\
\text { only be performed to the culprit vessel. }\end{array}$ & $\begin{array}{l}\text { After the procedure } \\
\checkmark \text { Assess the possibility of earlier discharge } \\
\text { and follow-up via telemedicine. } \\
\checkmark \text { Thorough terminal disinfection } \\
\text { after CCL procedures performed in } \\
\text { COVID-19 patients. } \\
\checkmark \text { Positive pressure with adequate } \\
\text { air changes can rapidly eliminate } \\
\text { the virus from the environment } \\
\text { and should be extended to rooms } \\
\text { associated with the procedure. } \\
\checkmark \text { Surveillance of the puncture site to } \\
\text { prevent hematomas. If possible, radial } \\
\text { compression bracelet and vascular } \\
\text { occlusion devices should be used, but } \\
\text { they add cost to the procedure. } \\
\checkmark \text { Educate patients and families on } \\
\text { the procedures performed and post- } \\
\text { procedural care (household recovery time, } \\
\text { puncture site surveillance, medication } \\
\text { use, telephone contact made available for } \\
\text { digital COVID-19 follow-up). } \\
\checkmark \text { Provide technical report with } \\
\text { description of the procedure, type and } \\
\text { amount of contrast used, medications } \\
\text { administered, radiological exposure } \\
\text { time and dose, complications. }\end{array}$ \\
\hline
\end{tabular}

A recent case series of 5700 inpatients with COVI-19 (median age, 63 years; male sex, 60.3\%) in the city of New York, United States, has reported a high prevalence of comorbidities, especially cardiovascular ones, as follows: arterial hypertension, $56.6 \%$; coronary artery disease, $11.1 \%$; heart failure, $6.9 \%$; obesity, $41.7 \%$; and diabetes, $33.8 \%$. Inhospital lethality rate was $21 \%$, which increased to $88 \%$ among those requiring mechanical ventilation. In addition, the authors have reported that most patients maintained their routine medications, such as angiotensin-converting enzyme inhibitors and angiotensin II receptor blockers. These data reinforce the need to maintain the traditional treatment of patients with heart diseases to avoid decompensation during the pandemic. ${ }^{29}$

The challenges presented during the COVID-19 pandemic are huge, not only the approach of patients with cardiovascular diseases, who need to continue their treatments regardless of having or not COVID-19, but also the management of the complex cardiovascular manifestations of SARS-CoV-2 infection, such as myocarditis, Takotsubo syndrome and myocardial injury, which can mimic ST-segment elevation myocardial infarction. In addition, patients usually delay seeking hospital treatment because of fear of contamination. ${ }^{30,31}$

During the COVID-19 pandemic, the established strategies, such as primary angioplasty, remain the standard treatment. These strategies should be performed at hospitals that are well equipped for a timely response and that have a team of specialized professionals wearing the aforementioned PPEs. The fibrinolysis-based strategy should be reserved for situations in which primary angioplasty cannot be performed. ${ }^{31}$

Although interventional cardiology certainly entails more engaging topics than safety, extraordinary times call for 


\begin{tabular}{|c|c|c|}
\hline COVID-19 & SAFETY RECOMMENDATIO & NS FOR CCL PROCEDURES \\
\hline $\begin{array}{l}\text { Ergonomics } \\
\checkmark \text { Tailor the workplace: layout, position } \\
\text { of the devices, room temperature (to } \\
\text { prevent work-related osteomuscular } \\
\text { disorders and repetitive strain injury). } \\
\checkmark \text { Maintain correct body posture, use } \\
\text { keyboards properly and maintain } \\
\text { screen at eye level; refine the use of } \\
\text { hands during injections, in managing } \\
\text { the manifold, guidewires and catheters; } \\
\text { stretch and relax at regular intervals. } \\
\text { Personal protective equipment } \\
\checkmark \text { The apron's size, model and cover area } \\
\text { should be tailored, as should its length } \\
\text { of use and its donning, doffing and } \\
\text { storing, to prevent cracks that hinder } \\
\text { its effectiveness. } \\
\checkmark \text { "Zero Gravity" lead apron - suspended } \\
\text { radiation protection system for the } \\
\text { body and head that allows freedom } \\
\text { of movement (alternative to the } \\
\text { conventional lead apron). } \\
\checkmark \text { Use of individual dosimeters, goggles } \\
\text { for X-ray radiation protection, thyroid } \\
\text { lead collars, non-slip closed shoes, } \\
\text { impermeable aprons, shoe covers, cap, } \\
\text { face mask, and hand gloves to avoid } \\
\text { contact with biological agents (blood, } \\
\text { secretions). } \\
\checkmark \text { Robot-assisted intervention provides } \\
\text { protection against radiation and better } \\
\text { ergonomics to the physician (CorPath } \\
\text { Robotic System). } \\
\text { Case Review } \\
\checkmark \text { CCL team meetings, which are useful and } \\
\text { effective tools to assess and solve CCL } \\
\text { events, should be conducted virtually } \\
\text { during the COVID-19 pandemic. }\end{array}$ & $\begin{array}{l}\text { Ionizing radiation } \\
\checkmark \text { Adhere to CCL safety rules: protection } \\
\text { against radiation in the walls, doors, and } \\
\text { control cabin; transparent lead screen; } \\
\text { CCL table with lead protection to arms } \\
\text { and legs (skirt) and lead screen attached to } \\
\text { ceiling; light and sound radiation warnings. } \\
\text { Professionals should keep the largest } \\
\text { possible distance from the radiation source. } \\
\checkmark \text { Keep radiation as low as reasonably } \\
\text { achievable (ALARA). } \\
\checkmark \text { Minimize fluoroscopy time and use low- } \\
\text { dose fluoroscopy. } \\
\checkmark \text { Limit frame rate (15 to } 7.5 \text { fps) } \\
\checkmark \text { Minimize the use of magnifications; use } \\
\text { filters and radiation field collimation; } \\
\text { use image already acquired as reference } \\
\text { in an additional screen; and limit } \\
\text { cineangiography. } \\
\checkmark \text { Adjust table height and image intensifier/ } \\
\text { flat-panel detector close to the patient. } \\
\checkmark \text { Avoid wide angulations in image } \\
\text { acquisition. } \\
\checkmark \text { Minimize the time of X-ray emission and } \\
\text { check the monitor for radiation dose. } \\
\checkmark \text { Perform preventive maintenance of } \\
\text { the equipment in accordance with the } \\
\text { International Commission on Radiological } \\
\text { Protection guidelines. } \\
\checkmark \text { Intravascular ultrasound (IVUS) and } \\
\text { optical coherence tomography (OCT/ } \\
\text { OFDI) reduce the radiation doses and } \\
\text { contrast amount used in long procedures; } \\
\text { contrast-free techniques are available. } \\
\checkmark \text { Pregnant patients should only be exposed } \\
\text { in case of extreme need, such as acute } \\
\text { myocardial infarction, with lead shielding } \\
\text { on the abdominal and pelvic regions. } \\
\checkmark \text { Pregnant healthcare workers should wear } \\
\text { double lead apron, according to each } \\
\text { region's legislation. }\end{array}$ & $\begin{array}{l}\text { Equipment } \\
\checkmark \text { Power generator to support occasional } \\
\text { drop in energy supply. } \\
\checkmark \text { The equipment should be tested } \\
\text { daily before initiating the procedures } \\
\text { (defibrillator, monitors, image } \\
\text { generation and storage). } \\
\checkmark \text { Procedure room with suitable } \\
\text { dimensions and well-placed equipment, } \\
\text { allowing better flow of workers and } \\
\text { patients, avoiding impact accidents } \\
\text { and orthopedic lesions of healthcare } \\
\text { professionals. } \\
\checkmark \text { Avoid accidents with piercing-cutting } \\
\text { materials by discarding them in a } \\
\text { specific waste container; at the end of } \\
\text { the procedure, their amount should } \\
\text { be checked with the professional who } \\
\text { prepared the table. } \\
\\
\text { Chemical and biological hazards } \\
\checkmark \text { Optimized plant regarding air quality. } \\
\checkmark \text { Automated hand washing sites close to } \\
\text { the procedure room. } \\
\checkmark \text { Keep to a minimum the circulation } \\
\text { in the procedure room, which should } \\
\text { remain closed. } \\
\checkmark \text { Prefer disposable materials and correctly } \\
\text { reprocess the reusable ones. } \\
\checkmark \text { Routine antibiotic prophylaxis is not } \\
\text { recommended, except for specific } \\
\text { procedures. } \\
\checkmark \text { SARS-CoV-2, a single-strand RNA } \\
\text { virus, is sensitive to ultraviolet } \\
\text { radiation and heat, being inactivated } \\
\text { by lipid solvents, such as ether (75\%), } \\
\text { ethanol, sanitizers containing chlorine, } \\
\text { peroxyacetic acid and chloroform, } \\
\text { except for chlorhexidine. } \\
\checkmark \text { Terminal disinfection should } \\
\text { be performed at the end of each } \\
\text { procedure. } \\
\checkmark \text { Disposable PPE, sheets, fabric, and } \\
\text { sponges contaminated with blood } \\
\text { should be placed into a waste container } \\
\text { marked with the biological hazard } \\
\text { symbol and disposed into a waste bin } \\
\text { labeled as 'COVID-19'. }\end{array}$ \\
\hline
\end{tabular}

extraordinary measures. It is essential to revisit the different aspects of protection for patients and healthcare personnel in the CCL, as well as to tailor them to the COVID-19 scenario.

Health systems around the world have been overwhelmed for months. However, unlike ventilators and wards, healthcare personnel cannot be 'manufactured' urgently, mainly highly specialized professionals, such as CCL staff. ${ }^{32}$
All activities performed in CCL rooms need to be restructured, and registries should be kept to quantify the effects of COVID-19 on the treatment of patients with cardiovascular diseases. In doing so, we will be able to learn from this pandemic and thereby both add value to this field and contribute to a rapidly growing body of knowledge on COVID-19. 
PUTTING ON AND REMOVING PPE FOR CCL PROCEDURES IN PATIENTS WITH SUSPECTED OR CONFIRMED COVID-19

\section{PUTTING ON PPE}

CCL anteroom

$\checkmark$ Remove any personal items

$\checkmark$ Hair should be fully held back

$\checkmark$ Perform hand hygiene and use $70 \%$ alcohol

$\checkmark$ Put on hair cap, covering the ears

$\checkmark$ Put on the facial mask FFP2/N95, fit flexible band to nose bridge and fit snug to face and below chin

$\checkmark$ Put on the goggles and face shield, placing them on top of hair cap and over face and eyes, adjusting to fit

$\checkmark$ Put on shoe covers

$\checkmark$ Put on protective lead apron or similar

$\checkmark$ Put on the impermeable gown

$\checkmark$ Perform hand disinfection with surgical scrubbing

$\checkmark$ Put on the first pair of gloves

Procedure room

$\checkmark$ - Put on the impermeable and sterile apron

$\checkmark$-Put on the second pair of gloves

\section{REMOVING PPE}

Procedure room (after patient has been transferred away)

$\checkmark$ Perform hand hygiene over the second pair of gloves with $70 \%$ alcohol

$\checkmark$ Peel off gown and second pair of gloves together and roll inside

$\checkmark$ Discard gown and gloves in a waste container marked with the biological hazard symbol and labeled as 'COVID-19' (avoid contact while removing the gown because of the contamination risk)

$\checkmark$ Perform hand hygiene over the first pair of gloves with 70\% alcohol

$\checkmark$ Remove hair cap, shoe cover and goggles

$\checkmark$ Perform hand hygiene over the first pair of gloves with 70\% alcohol

CCL anteroom

$\checkmark$ Remove the first pair of gloves

$\checkmark$ Remove the respiratory PPE (surgical mask, facial shield, FFP2/N95 respirator)

$\checkmark$ Perform hand hygiene with $70 \%$ alcohol

$\checkmark$ Remove lead apron or similar

$\checkmark$ Perform proper hand hygiene

Figure 3 - Steps for putting on and removing PPE for cardiac catheterization laboratory (CCL) procedures during the COVID-19 pandemic. . $^{4,512-14,28}$

\section{Author contributions}

Conception and design of the research: Mariano GZ, Lenke V, Paiva MSM, Oliveira GMM. Acquisition of data: Mariano GZ, Lenke V, Paiva MSM, Oliveira GMM. Analysis and interpretation of the data: Mariano GZ, Lenke V, Paiva MSM, Oliveira GMM. Writing of the manuscript: Mariano GZ, Lenke V, Paiva MSM, Oliveira GMM. Critical revision of the manuscript for intellectual content: Mariano GZ, Lenke V, Paiva MSM, Oliveira GMM.

\section{References}

1. Dong E, Du H, Gardner L. An interactive web-based dashboard to track COVID-19 in real time. Lancet Infect Dis. 2020;20(5):533-4.

2. Oliveira GMM, Pinto FJ. COVID-19: A Matter Close to the Heart. Int J Cardiovasc Sci. 2020; ahead print. Epub Apr 17,2020.

3. Driggin E, Madhavan MV, Bikdeli B, Chuich T, Laracy J, Bondi-Zoccai G, et al. Cardiovascular Considerations for Patients, Health Care Workers, and Health Systems During the Coronavirus Disease 2019 (COVID-19) Pandemic, J Am Coll Cardiol. 2020 Mar 18, Pii:S0735-1097(20)34637-4 [Epub ahead of print]

4. Welt FGP, Shah PB, Aronow HD, Bortnick AE, Henry TD, Sherwood MW, et al., from the American College of Cardiology's (ACC) Interventional Council and the Society of Cardiovascular Angiography and

\section{Potential Conflict of Interest}

No potential conflict of interest relevant to this article was reported.

\section{Sources of Funding}

There were no external funding sources for this study.

\section{Study Association}

This study is not associated with any graduation program.

Intervention (SCAI), Catheterization Laboratory Considerations During the Coronavirus (COVID-19) Pandemic: From ACC's Interventional Council and SCAI. J Am Coll Cardiol. 2020; doi: https://doi.org/10.1016/j. jacc.2020.03.031.

5. Sociedade Brasileira de Hemodinâmica e Cardiologia Intervencionista. (SBHCI). Comunicado n ${ }^{\circ}$ 04/2020. Posicionamento da Sociedade Brasleira de Hemodinâmica e Cardiologia Intervencionista sobre a Pandemia COVID-19. [Citado em 2020 Apr 30] Disponível em: sbhci.org/post/ comunicado 04-2020 www.sbhci.org.br

6. Wu Z, McGoogan JM. Characteristics of and Important Lessons from the Coronavirus Disease 2019 (COVID-19) Outbreak in China:Summary of a Report of 72314 Cases From the Chinese Center for Disease Control 
and Prevention. JAMA.2020 Feb 24. [Cited 2020 April 16]. Available from:https: Available from: doi: 10.1001/jama/2020.2448

7. Huh S. How to train health personnel to protect themselves from SARS-CoV-2 (novel coronavirus) infection when caring for a patient or suspected case.J educ Eval Health Prof.2020;17:10. Doi:10.3352/ jehp.2020.17.18

8. Naidu SS,Aronow H, Box L, Daffy PL, Kolansky DM, Kupfer JM. SCAI Expert Consensus Statement: 2016 Best Practices in the Cardiac Catheterization Laboratory: (Endorsed by the Cardiological Society of India, and Sociedad Latino Americana de Cardiologia Intervencionista; Affirmation of Value by the Canadian Association of Interventiona Cardiology-Association Canadienne de Cardiologie d'intervention)* Cath Cardiovasc Interv. 2016;88(3):407-23.

9. Zeng J, Huang J, Pan L. How to balance acute myocardial infarction and COVID-19: the protocols from Sichuan Provincial People's Hospital. Intensive Care Med. 2020 Feb 26. doi: 10.1007/s00134-020-05993-9

10. Koh D. Occupational risks for COVID-19 infection. Occup Med (London) 2020;70(1):3-5. doi:10.1093/occmed/kqaa036

11. Costa I, Bittar C, Rizk S, Araujo Filho AE, Santos KQ, Machado T, et al. The Heart and COVID-19: What cardiologists need to know. Arq Bras Cardiol-diol. 2020; [online].ahead print, PP.0-0. DOI: https://doi. org/10.36660/abc.20200279

12. Szerlip M, Anwaruddin S, Aronow HD, Cohen MG, Daniels MJ, et al. Considerations for Cardiac Catheterization Laboratory Procedures Dur-ing the COVID-19 Pandemic. Perspectives from the Society for Cardiovascular Angi-ography and Interventions Emerging Leader Mentorship (SCAI ELM) Members and Grad-uates. doi: 10.1002/ccd.28887

13. Tarantini G, Fraccaro C, Chieffo A, Marchese A, Tarantino F, Rigattieri S, et al. Italian Society of Interventional Cardiology (GISE) position paper for Cath lab-specific preparedness recommendations for healthcare providers in case of suspected, probable or confirmed cases of COVID-19. Catheter Cardiovasc Interv. 2020; 1-5. https://doi.org/10.1002/ccd.28888

14. ESC Guidance for the Diagnosis and Management of CV Disease during the COVID-19 Pandemic. Eur Soc Cardiol. 2020 Apr 21. [Cited in 2020 April 21]. Available from: https://www.escardio.org/Education/COVID19-and-Cardiology/ESC-COVID-19-Guidance

15. Shereen MA, Shereen MA, khan S, Kazmi A, Bashir N, Siddique R. COVID-19 infection: Origin, transmission, and characteristics of human coronaviruses. J Adv Res. 2020;24:91-8. doi.org/10.1016/j.jare.2020.03.005

16. Andreassi MG, Picalluga E, Guagliumi G, Del Greco M, Gaita F, Picano F. Occupational health risks in cardiac catheterization laboratory workers. Circ Cardiovasc Interv. 2016; 9(4):e003273.

17. Christopoulos G, Makke L, Kolsia A, Rangan BV, Roesle M. Optimizing Radiation Safety in the Cardiac Catheterization Laboratory: A Practical Approach. Catheter Cardiovasc Interv. 2016;87(2):291-301.

18. Sun Z, Abazis A, Yusof AK. Radiation-induced noncancer risks in interventional cardiology: optimisation of procedures and staff and patient dose reduction. Biomed Res Int. 2013;2013.976962

19. Fetterly KA, Mathew V, Lennon R, Bell MR, Holmes DR Jr, Rihal CS, et al. Radiation Dose Reduction in the Invasive Cardiovascular Laboratory Implementing a Culture and Philosophy of Radiation Safety. JACC:Cardiovasc Interv. 2012;5(8):866-73.
20. Agarwal S, Parashar A, Ellis SG, Heupler FA Jr, Lau E, Tuzcu EM, et al. Measures to reduce radiation in a modern cardiac catheterization laboratory. Circ Cardiovasc Interv, 2014;7(4):447-55

21. Agência Nacional de Vigilância Sanitária. (Anvisa). Gerência de Vigilância e Monitoramento em Serviços de Saúde Gerência Geral de Tecnologia em Serviços de Saúde. Nota Técnica GVIMS/GGTES/ Anvisa No 04/2020 orientações para serviços de saúde: medidas de prevenção e controle que devem ser adotadas durante a assistência aos casos suspeitos ou confirmados de infecção pelo novo coronavirus (SARS-COV-2); 31 mar. 2020

22. Best PJ, Skelding KA, Mehran R, Chieffo A, Kunadian V, Madan M,et al. SCAI Consensus Document on Occupational Radiation Exposure to the Pregnant Cardiologist and Technical Personnel. Catheter Cardiovasc Interv. $2011 \mathrm{Feb}$ 1;77(2):232-41.

23. Gurm HS, Dixon SR, Smith DE, Share D, Lafonde T, Greenbaum A, et al. Renal Function-Based Contrast Dosing to Define Safe Limits of Radiographic Contrast Media in Patients Undergoing Percutaneous Coronary Interventions. J Am Coll Cardiol. 2011;58(9):907-14.

24. Kern M. Cath Lab Safety. CathLabDigest. 2020 Apr 24;22(4)

25. Picano E. The appropriate and justified use of medical radiation in cardiovascular imaging: a position document of the ESC Associations of Cardiovascular Imaging, Percutaneous Cardiovascular Interventions and Electrophysiology. Eur Heart J. 2014; 35(10):865-72.

26. Azzalini L, Laricchia A, Regazzoli D, Mitomo S, Hachinohe D, Bellini B,et al. Ultra-Low Contrast Percutaneous Coronary Intervention to Minimize the Risk for Contrast-Induced Acute Kidney Injury in Patients With Severe Chronic Kidney Disease. J Invasive Cardiol. 2019 Jun;31(6):176-82. Epub 2019 Mar 15

27. Romaguera R, Gonzalez IC, Ojeda S, Jimenez-Candil J, Calvo D, Garcia Seara J, et al. Gestión de salas de procedimientos invasivos cardiológicos durante el brote de coronavirus COVID-19. Documento de consenso de la Asociación de Cardiología Intervencionista y la Asociación del Ritmo Cardiaco de la Sociedad Española de Cardiología Rafael Romagueraa. REC Interv Cardiol. REC Interv Cardiol. 2020; ahead print. Epub Mar 16,2020. doi: https://doi.org/10.24875/RECIC.M20000114.

28. Ierardi AM, Wood BJ, Gaudino C, Angileri SA, Jones EC, Hauseggers $\mathrm{K}$, et al. How to Handle a COVID-19 Patient in the Angiographic Suite. Cardiovasc Intervent Radiol. 2020 Apr 10. doi: https://doi.org/10.1007/ s00270-020-02476-8

29. Richardson S; Hirsch JS, Mangala N, Crawford JM, McGinn T, Davidson $\mathrm{K}$, and Northwell COVID-19 Research Consortium. Presenting Characteristics, Comorbidities, and Outcomes Among 5700 Patients Hospitalized With COVID-19 in the NewYork City Area. JAMA. 2020 Apr 22 doi:10.1001/jama.2020.6775

30. Rosenbaum L. The Untold Toll - The Pandemic's Effects on Patients without Covid. N Engl J Med. 2020 Apr 17. Doi:10.1056/ NEJMms2009984

31. Mahmud E, Dauerman HL, Welt FG, Messenger IC, Rao SV, Grines C, et al. Management of acute myocardial infarction during the COVID-19 pandemic,. J Am Coll Cardiol. 2020 April 20. doi: https://doi.org/10.1016/j. jacc.2020.04.039.

32. McCartney M. Medicine: before COVID-19, and after. The art of medicine-perspectives. Lancet. 2020 Ar 20;395(10232):1248-9. 